\title{
Successful retrieval of dislocated inferior vena cava filter using double vascular sheaths docking technology: case report
}

\author{
Mi Zhou, Lixing Qi and Yongquan Gu*
}

\begin{abstract}
Background: Dislocation of inferior vena cava filter (IVCF) is a rare complication with potential IVC perforation and other life-threatening risks requiring early diagnosis and in-time retrieval. Most of dislocation IVCF in the past have been shelved or removed by open surgery. It is very difficult to retrieve the filters by interventional technology.

Case presentation: Here we report a 49-year-old man suffering from dislocation of IVCF implanted due to deep vein thrombosis (DVT) in the right femoral vein. Successful retrieval of the IVCF using double sheaths docking technique was done soon after confirmation of the dislocation. Importance of monitoring and early detection of dislocation of IVCF should be emphasized to avoid further complications.

Conclusions: The double vascular sheaths docking technique can be considered as a preferential option in difficult operative situation.
\end{abstract}

Keywords: IVCF, Dislocation, Deep vein thrombosis

\section{Background}

DVT in lower extremities occurs under conditions of venous endothelial damage, blood hypercoagulation, and stasis. The main risks of DVT include early fatal pulmonary embolism (PE) and late pulmonary hypertension. For patients with anticoagulation contraindications and recurrent DVT, IVCF should be implanted to prevent fatal PE. Furthermore, monitoring on IVCF status is critical to guarantee its' thrombus capture effect and reduce filter-derived complications.

IVCF-derived adverse events have been reported as placement issues (45.1\%), IVC penetration (29.9\%) and IVC filter fracture (27.1\%) [1-5]. At the same time, related data suggested a high rate of serious complications after temporary IVCF implantation, calling for the urgency of strictly following indications of IVCF and

\footnotetext{
* Correspondence: guyqvip@126.com

Department of Vascular Surgery Xuanwu Hospital, Capital Medical University No. 45 Changchun Street, Xicheng District 100053 Beijing P. R. China
}

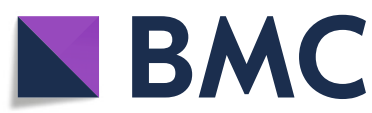

( The Author(s). 2021 Open Access This article is licensed under a Creative Commons Attribution 4.0 International License, which permits use, sharing, adaptation, distribution and reproduction in any medium or format, as long as you give appropriate credit to the original author(s) and the source, provide a link to the Creative Commons licence, and indicate if changes were made. The images or other third party material in this article are included in the article's Creative Commons licence, unless indicated otherwise in a credit line to the material. If material is not included in the article's Creative Commons licence and your intended use is not permitted by statutory regulation or exceeds the permitted use, you will need to obtain permission directly from the copyright holder. To view a copy of this licence, visit http://creativecommons.org/licenses/by/4.0/ The Creative Commons Public Domain Dedication waiver (http://creativecommons.org/publicdomain/zero/1.0/) applies to the data made available in this article, unless otherwise stated in a credit line to the data.

\section{Case presentation}

A 49-year-old man with DVT in right femoral vein following ruptured cerebral aneurysm underwent retrievable IVCF (Denali, Bard, USA) implantation to prevent fatal PE. Pharmoco-mechanical thrombectomy was performed with angiojet system (Boston Scientific, MA, USA). During the surgery, a leg of the filter was found to be dislocated (Fig. 1A), which may cause perforation of the vena cava and retroperitoneal hematoma [6, 7]. With the help of disposable biopsy forceps (KLF-A, Hangzhou, China) (Fig. 1B), the dislocated filter leg was taken into an $8 \mathrm{~F}$ vascular sheath (Fig. 1C). Then routine 

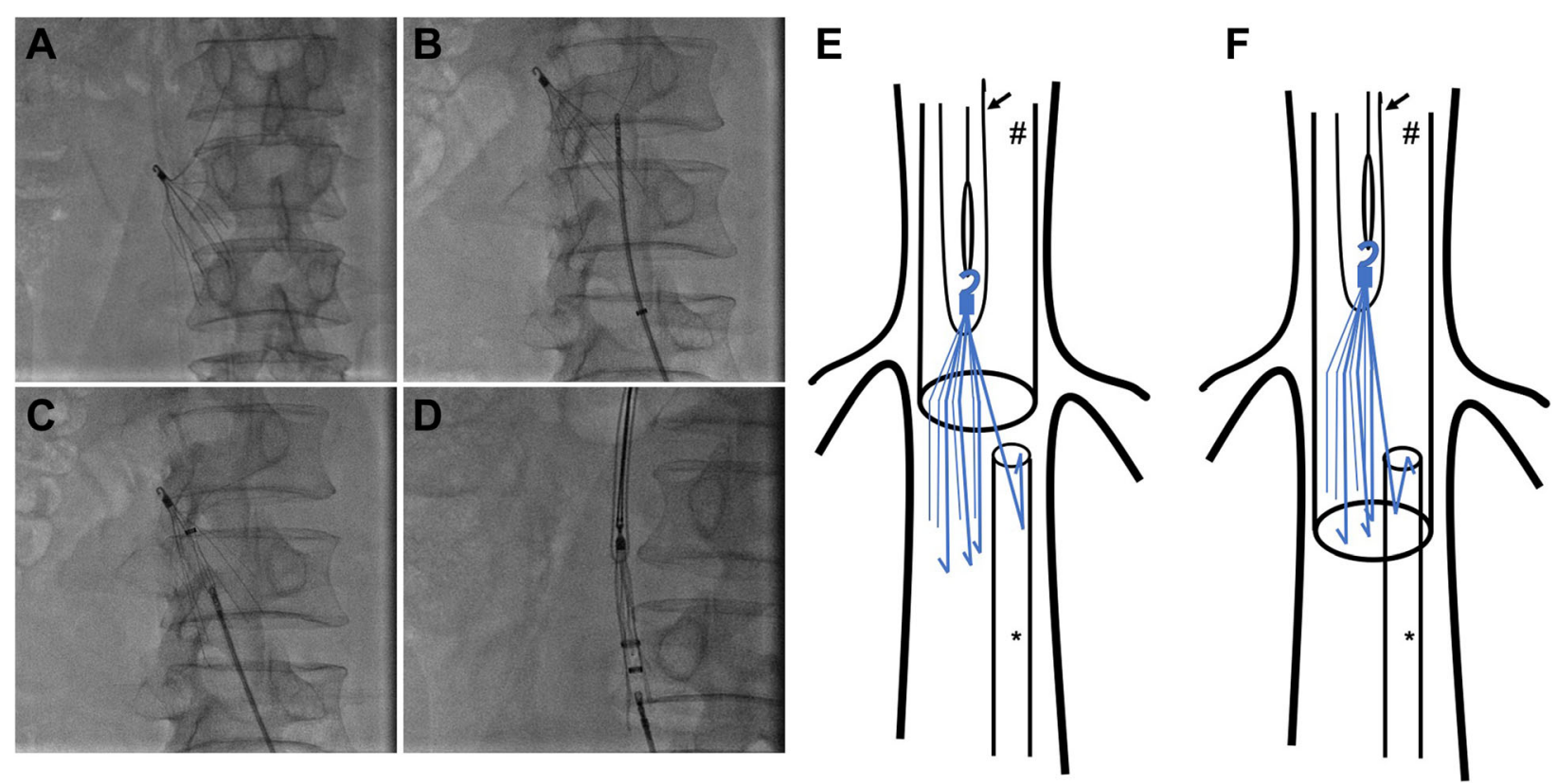

Fig. 1 Combination of double sheaths docking technique and Loop-Snare technique to retrieve the IVC filter. (A) One leg of the filter is dislocated and bent cephalad. (B-C) use of disposable biopsy forceps to retrieve the dislocated filter leg into an 8 F vascular sheath, (D) push the $13 \mathrm{~F}$ vascular sheath downwards to complete the docking of the two vascular sheaths and retrieve the filter, (E-F) model for double sheaths docking technique to retrieve the filter. ${ }^{*} 8 \mathrm{~F}$ sheath; \# $13 \mathrm{~F}$ sheath; $\rightarrow 0.035$ in. hydrophilic guide wire

filter retrieval (13F) procedures were carried out via jugular vein approach but failed to trap the filter hook due to filter tilt and hook apposition to the cava wall. The "Loop-Snare Technique" [8] was used to trap the filter hook with continuous push of the $13 \mathrm{~F}$ sheath downwards to the $8 \mathrm{~F}$ one to complete docking of the two vascular sheaths, resulting in successful retrieval of the filter (Fig. 1D). During the retrieval procedures, the entire filter was kept in the lumen of the two vascular sheaths to avoid possible injury to the vena cava (Fig. 1E-F).

\section{Discussion}

IVCF is an absolutely therapeutic choice for avoiding fatal PE when conventional anticoagulation is contraindicated or deemed ineffective [9]. A retrievable filter was our choice for the patient on considering the patient's age and relatively good clinical expectation. In view of functional design, the axial stability of the temporary filter in the inferior vena cava is worse than the permanent one $[2,3]$, so postoperative monitoring of the filter is the key to maintain a good thrombus interception effect and avoid filter-related complications. Related studies on the long-term complications of filter concluded that most adverse events related to IVCF were device migration (35.6\%), fractured parts embolization (15.9\%) and IVC perforation $(7.6 \%)[2,3]$. In our vascular center, approximately 250 patients receive IVCF implantation due to suffering DVT of lower extremities each year. The most common adverse events were the poor axial tilt and the displacement of the IVCF, resulting in the difficulty in IVCF retrieval. Hemodynamics change of the IVC due to ventilation and cardiopulmonary resuscitation has been considered as the main factors contributing to filter dislocation $[10,11]$. Previous studies have reported multiple cases of cardiac tamponade caused by filter dislocation $[9,12-16]$ with serious consequences. Therefore, complications related to filter dislocation require prompt treatment.

This case revealed filter leg dislocation and axial migration of the filter. The dislocated filter leg may not only causes perforation of the inferior vena cava, resulting in retroperitoneal hematoma [17], and causes injure to the intestine, pancreas, aorta [18], but also leads to leg fracture of filter during retrieving of the filter. Nishikawa $\mathrm{T}$ reported that the dropped part of fractured filter leg was difficult to retrieve and had to be left in the vena cava [19]. However, recent studies demonstrated the safety and technically feasibility of endovascular retrieval of the filter that penetrated adjacent intestine [18] and adjacent vertebrae [20]. In our case, we successfully retrieve the dislocated IVCF combined with the filter tilting exceeds 25 degrees, which is often regarded as one of the important reasons for the difficulty of retrieval [21], the possible reasons are as follows: (1) The close follow-up allowed us to discover the displacement of the filter promptly, and the foot of the filter has not penetrated the vena cava; (2) Double vascular sheaths docking technology is beneficial to correct the axial direction 
of the filter. To our knowledge, this is the first case reporting the double sheaths docking to retrieve the dislocated filter, the docking with double vascular sheaths to retrieve the filter has the following advantages: (1) the dislocated filter leg was kept with the head-side orientation, avoiding damage to the vena cava by the barbed leg (2) the dislocated filter leg is protected by the vascular sheath, limiting the movement range of the leg, and avoiding the possibility of secondary dislocation of the leg. Recent study reviewed the complications of IVCF malfunction including the penetration, fracture, or migration of the device, and assessed the result of open surgery retrieval and endovascular retrieval. Comparing to the open surgery retrieval, endovascular retrieval of IVCF has a significantly lower likelihood of thromboembolic complication, and a trend to lower infectious complications, mortality, hospital costs, however, with no statistical significance [22]. Therefore, endovascular retrieval of dislocated IVCF may have obvious advantages compared with open surgery due to its minimal invasiveness and safety. This report aims to highlight the importance of postoperative filter monitoring to avoid serious filter-derived complications. The double vascular sheaths docking technique can be considered as a preferential method to retrieve dislocated IVCF.

\section{Conclusion}

Dislocation of the IVCF is a rare and serious complication, calling for our sufficient attention. Monitoring on IVCF status is critical to guarantee its' thrombus capture effect and reduce filter-derived complications. The double vascular sheaths docking technique can be considered as a superior method.

\section{Abbreviations \\ IVCF: Inferior vena cava filter; DVT: Deep vein thrombosis; PE: Pulmonary embolism}

\section{Acknowledgements}

None.

\section{Authors' contributions}

Mi Zhou and Yongquan Gu designed the methods, analyzed the data and results, Mi Zhou and Lixing Qi wrote the manuscript and prepared figures. All authors have read and agreed to the published version of the manuscript.

\section{Funding}

This study was supported by the National Key Research and Development Program of China (No. 2017YFC1104100)

\section{Availability of data and materials}

All data analyzed during our study are included within the published article.

\section{Declarations}

\section{Ethics approval and consent to participate}

The study was approved by the Ethics Committee of Xuanwu Hospital affiliated with Capital Medical University. Written patient consent for participation was obtained.

\section{Consent for publication}

Written patient informed consent for participation was obtained. All authors have read and agreed to the published version of the manuscript.

\section{Competing interests}

The authors declare that they have no conflict of interest.

Received: 24 March 2021 Accepted: 5 August 2021

Published online: 17 August 2021

\section{References}

1. Stavropoulos SW, Sing RF, Elmasri F, Silver MJ, Powell A, Lynch FC, et al. The DENALI Trial: an interim analysis of a prospective, multicenter study of the Denali retrievable inferior vena cava filter. J Vasc Interv Radiol. 2014;25:14971505, 1505 e1491.

2. Ayad MT, Gillespie DL. Long-term complications of inferior vena cava filters. J Vasc Surg Venous Lymphat Disord. 2019;7:139-44.

3. Wang SL, Siddiqui A, Rosenthal E. Long-term complications of inferior vena cava filters. J Vasc Surg Venous Lymphat Disord. 2017;5:33-41.

4. Zhou D, Spain J, Moon E, McLennan G, Sands MJ, Wang W. Retrospective review of 120 celect inferior vena cava filter retrievals: experience at a single institution. J Vasc Interv Radiol. 2012;23:1557-63.

5. Stoneham GW, Burbridge BE, Millward SF. Temporary inferior vena cava filters: in vitro comparison with permanent IVC filters. J Vasc Interv Radiol. 1995:6:731-6

6. Miller CL, Wechsler RJ. CT evaluation of Kimray-Greenfield filter complications. AJR Am J Roentgenol. 1986;147:45-50.

7. Greenfield LJ. Perforation of the inferior vena cava with aortic and vertebral penetration by a suprarenal Greenfield filter. Radiology. 1990;175:287.

8. Rubenstein L, Chun AK, Chew M, Binkert CA. Loop-snare technique for difficult inferior vena cava filter retrievals. J Vasc Interv Radiol. 2007;18: 1315-8

9. Mocavero PE, Stagliano A, Coppola M, Langella S, Conte A, Pappalardo F, et al. An unusual cause of cardiogenic shock: tricuspid regurgitation and right ventricular perforation due to vena cava filter migration. HSR Proc Intensive Care Cardiovasc Anesth. 2012:4:47-50.

10. Laborda A, Kuo WT, loakeim I, De Blas I, Malve M, Lahuerta C, et al. Respiratory-induced Haemodynamic changes: a contributing factor to IVC filter penetration. Cardiovasc Intervent Radiol. 2015;38:1192-7.

11. Chalhoub V, Richa F, Hachem K, Slaba S, Yazbeck P. Contributing factors to inferior vena cava filter migration. Cardiovasc Intervent Radiol. 2015;38: 1676-7.

12. Lorch $H$, Welger D, Wagner V, Hillner B, Strecker EP, Herrmann H, et al. Current practice of temporary vena cava filter insertion: a multicenter registry. J Vasc Interv Radiol. 2000;11:83-8.

13. Millward SS. Buckling of the tethering catheter causes migration of a temporary caval filter to the right atrium. Clin Radiol. 2000:55:652-3.

14. Rossi P, Arata FM, Bonaiuti P, Pedicini V. Fatal outcome in atrial migration of the Tempofilter. Cardiovasc Intervent Radiol. 1999:22:227-31.

15. Bovyn G, Gory P, Reynaud P, Ricco JB. The Tempofilter: a multicenter study of a new temporary caval filter implantable for up to six weeks. Ann Vasc Surg. 1997;11:520-8.

16. Sakai $Y$, Masuda $H$, Arai G, Kobayashi T, Kageyama $Y$, Kihara K Accidental dislocation of an intracaval temporary filter into the heart in a case of renal cell carcinoma extending into the vena cava. Int J Urol. 2006;13:1118-20.

17. Seita J, Sakakibara Y, Jikuya T, Shigeta O, Nakata H, Tsunoda H, et al. Surgical management of a penetrated greenfield inferior vena cava filter. Thorac Cardiovasc Surg. 2001;49:243-4.

18. Joe WB, Larson ML, Madassery S, Devane AM, Holly BP, Sing RF, et al. Bowe penetration by inferior vena cava filters: feasibility and safety of percutaneous retrieval. AJR Am J Roentgenol. 2019;213:1152-6.

19. Nishikawa T, Oka T, Shioyama W, Kashimoto K, Yasui T, Oboshi M, et al. Fracture of a retrievable inferior vena cava filter placed for Cancerassociated thrombosis in a patient with malignant lymphoma. Intern Med. 2020;59:673-6.

20. McCafferty BJ, Joe WB, Meh Chu G, Devane AM, Madassery S, Gunn AJ. Penetration of bone by inferior vena cava filters: safety and technical success of percutaneous retrieval. Curr Probl Diagn Radiol. 2021;50:662-4 
21. Rosenthal D, Wellons ED, Hancock SM, Burkett AB. Retrievability of the Gunther tulip vena cava filter after dwell times longer than 180 days in patients with multiple trauma. J Endovasc Ther. 2007;14:406-10.

22. Kim TI, Abougergi MS, Guzman RJ, Ochoa Chaar Cl. Costs and complications of hospital admissions for inferior vena cava filter malfunction. J Vasc Surg Venous Lymphat Disord. 2021;9:315-20 e314.

\section{Publisher's Note}

Springer Nature remains neutral with regard to jurisdictional claims in published maps and institutional affiliations.

Ready to submit your research? Choose BMC and benefit from:

- fast, convenient online submission

- thorough peer review by experienced researchers in your field

- rapid publication on acceptance

- support for research data, including large and complex data types

- gold Open Access which fosters wider collaboration and increased citations

- maximum visibility for your research: over $100 \mathrm{M}$ website views per year

At BMC, research is always in progress.

Learn more biomedcentral.com/submissions 